\section{A timely wake-up call as anti-evolutionists publicize their views}

SIR - Your Special Report "Antievolutionists raise their profile in Europe" (Nature 444, 406-407; 2006) mentions a seminar held in Brussels at the European Parliament on 11 October 2006, as part of a new strategy by supporters of intelligent design (ID) to disseminate anti-evolutionism among the general public of Europe. Two days later, the Catholic Kolbe Center for the Study of Creation and the creationist group Truth in Science published summaries on the Internet. A moderator of the seminar, Maciej Giertych, then published a Correspondence ("Creationism, evolution: nothing has been

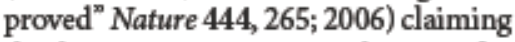
that his arguments are entirely scientific and denying any religious component to them. I believe, therefore, that it was a good decision by Nature to publish this Correspondence, as a wake-up call to scientists.

The anti-evolution seminar was a series of three public lectures, introduced and moderated by Giertych, who is the retired head of the genetics department of the Polish Academy of Sciences and an honorary member of the Daylight Origins Society, a Catholic creationist organization based in Britain. The seminar was co-organized by Dominique Tassot, director of the Centre d'Etude et de Prospectives sur la Science, an association of 700 Catholic intellectuals who do not accept macroevolution because it is in conflict with their interpretation of the Bible (see Nature 439, 534; 2006).

At the meeting, Giertych pointed out that macroevolution (the gradual appearance of novel body plans as documented in the fossil record) is a "falsified hypothesis" and that there is, from genetics research, no evidence but "only disproof" for Darwin's principle of common descent of all life on Earth.

These claims were supplemented by Joseph Mastropaolo, a US aerospace physiologist, who argued that the theory of evolution, after more than 150 years, "still lacked any empirical proof .

The German civil engineer HansJoachim Zillmer told the audience that the fossil record does not provide evidence for gradual macroevolution. Zillmer was announced as an expert in palaeontology and evolution, but he has not, according to the Web of Science, published any paper in the peer-reviewed literature. $\mathrm{He}$ is the author of popular books with titles such as Darwin's Mistake (Adventures Unlimited Press, 2003) or Die Evolutionslugge (The Evolution Lie Langen Müller, 2005). In Darwin's Mistake, Zillmer asserts that he has found human and dinosaur footprints in fossil-bearing sediments in a riverbed in Texas and concludes that these organisms lived together. Even creationists no longer daim that these supposed 'human prints' are genuine (see Nature 323, 390; 1986). Zillmer's books state that biologists, geologists and the editors of most scientific journals are either misled or fools.

Finally, Guy Berthault told the audience about his research on the rates of sediment depositions, which "did not form slowly over millions of years", but "have been laid down within very short time periods. Hence, according to Berthault, most geological data on the age of fossils must be wrong. Giertych's controversial letter is a brief summary of these anti-evolution, pro-ID-lectures. U. Kutschera

Institute of Biology, University of Kassel, Heinrich-Plett-Strasse 40,

D-34109 Kassel, Germany

\section{Creationist views have no basis in science}

SIR — Maciej Giertych signed his Correspondence letter (Nature 444, 265; 2006) as an employee of the Institute of Dendrology, the Polish Academy of Sciences. As the director of the institute, I would like to point out that, although I respect Professor Giertych's rights to express his views, they are not endorsed by our institute. In my opinion, creationism has no basis in science and should not be regarded as scientific. Gabriela Lorenc-Pluciniska Institute of Dendrology, Polish Academy of Sciences, Kórnik, Poland

\section{Creationists weaken society's trust in scientists}

SIR - As a scientist I wassurprised, and as a Polish scientist I felt ashamed, to read Maciej Giertych's view published in Nature (Nature $444,265 ; 2006)$. I would like to assure you that biologists in Poland do follow current scientific findings and would strongly disagree with several statements made in that letter.

There is no accepted scientific evidence for his most ridiculous claims exclusively harmful mutations, reduction of genetic information or the coexistence of dinosaurs and humans. The only statements I would agree with are that scientists have to search for explanations of what they see in the world around them, and that they should be critical about both new and well established findings.

Polish politicians' recent denial of the theory of evolution is very dangerous, not only because it goes against the scientific paradigm, but also because it weakens society's trust in scientists and in research. Our protests have gained support even from Polish academics with religious connections, such as Catholic lecturers in the philosophy of nature. The publication of unsubstantiated claims and incorrect statements in renowned scientific journals gives undeserved support to the creationist movement.

Joanna Rutkowska

Institute of Enviranmental Sciences, bgiellonian University, Gronostajowa 7,30-387 Kraków, Poland

\section{Claim of bias against critics is refuted by publication}

SIR - Maciej Giertych states in Correspondence (Nature 444, 265; 2006): ${ }^{\circ} \mathrm{I}$ believe that, as a result of media bias, there seems to be total ignorance of new scientific evidence against the theory of evolution." However, hedoes not refer to one publication in a peer-reviewed scientific journal to support the existence of any such "new scientific evidence"; nor has he himself published any. Until any such publication, the existence of scientific evidence against evolution remains unsubstantiated. Further, where is the bias of which Giertych speaks? The very fact that his letter was published shows that Nature has no bias against critics of evolution.

Gerdien de Jong ${ }^{\star}$, Gert Korthof

"Evolutionary Population Biology, Utrecht University, Padualaan 8, NL-3584 CH Utrecht, the Netherlands †Bilthoven, the Netherlands

\section{Pseudoscience should not be published in Nature}

SIR - Although we acknowledge the need to allow publication of diverse opinions in the name of free speech, Nature has a responsibility, as a leading and widely read science journal, to uphold scientific standards and values. Unfortunately, in Maciej Giertych's Correspondence letter ( ${ }^{\circ}$ Creationism, evolution: nothing has been proved $^{\text {}}$ Nature 444, 265; 2006), Nature fell short in this duty, allowing creationist pseudoscientific arguments to be presented as fact, without any supporting evidence.

The arguments used by Giertych are widely used by creationists, and, in their pseudoscientific tradition, evidence that discredits them is constantly ignored. For example, his suggestion that dinosaurs coexisted with humans, presumably based on supposed human footprints found alongside those of dinosaurs in the Glen Rose Formation of Texas (as expounded by Henry M. Morris in Scientific Creationism CLP Publishers, 1974) has been refuted: the human' footprints are now recognized as dinosaurian (R. Hastings J. Geol. Educ. $35,4-15 ; 1987)$. A comprehensive source that scientifically discredits such 'evidence' can be found at http://scienceblogs.com/ 